\title{
Detection and Measurements of Cracks in Axially Loaded Tension RC Members by Image Processing Technique
}

\author{
Md. Mahfuzur Rahman*, Ismail Saifullah, Sunthonu Kumar Ghosh \\ Department of Civil Engineering, Khulna University of Engineering \& Technology (KUET), Bangladesh \\ *Corresponding author: mahfuz11@ce.kuet.ac.bd
}

Received February 03, 2019; Revised March 17, 2019; Accepted April 07, 2019

\begin{abstract}
Concrete cracking is very common and appeared in all types of concrete structures. Detection of concrete crack initiation and measurement of their characteristics has been a part of structural monitoring and maintenance program. Though manual inspection of cracks in the concrete structure is the oldest and still an accepted method of crack measurements, a more accurate technique for crack detection and measurement, applicable for all kind of concrete structures, is required. Automatic crack identification and crack width measurement by the image analysis method has been gaining popularity due to its versatile applicability, more accuracy and safety standard in difficult situations. In this context, the image analysis method is adopted in laboratory testing of the concrete prism with reinforcement under axial tension to identify and measure cracks in concrete prism samples. In this research work, a crack quantification method based on 2D image analysis is utilized. Raw colour images (RGB images) were obtained by means of a camera for cracks formed due to axial tension in reinforcement. Processing of RGB images with sufficient information will provide the dimension of crack. For all the image post-processing, an open source ImageJ software was utilized and characteristics of cracks were automatically determined by Ridge Detection Plugin. The results of image processing were also verified with the results from microscopic measurement of cracks in reinforced concrete prism samples.
\end{abstract}

Keywords: axial tension, concrete, crack width, image processing, microscopic, ImageJ

Cite This Article: Md. Mahfuzur Rahman, Ismail Saifullah, and Sunthonu Kumar Ghosh, "Detection and Measurements of Cracks in Axially Loaded Tension RC Members by Image Processing Technique.” American Journal of Civil Engineering and Architecture, vol. 7, no. 2 (2019): 115-120. doi: 10.12691/ajcea-7-2-5.

\section{Introduction}

In construction industries, most of the structures are made of concrete. Durability of these concrete structures is very crucial factors in both construction and maintenance phase. Various surface cracks can be appeared from even the beginning of the construction of these structures. Presence of cracks in concrete implies the aesthetical discomfort as well as the onset of severe damage of the structures [1,2,3,4]. Therefore, routine inspection of concrete structures for surface crack is utmost important for structure health monitoring plans $[5,6]$ and has been a part of structural monitoring and maintenance program. Three major categories for detecting and measuring cracks are found in literature - human inspection, microscopic inspection and automatically by image analysis [7]. Generally, first two methods involve direct interaction of inspectors and therefore encounter subjective judgment. Moreover, those methods are very time consuming and quite difficult to access full structure. Therefore, many researchers have suggested image processing techniques to detect and measure crack quickly and in an efficient way. Automatic crack detection and characteristics of cracks measurement reduces inspection time and increases inspection accuracy as well as the safety standards of inspection procedure.

Researchers have been analyzing the image analysis method in the various field of studies as well as in concrete crack analysis. They have been using raw colour images with lots of information and processing them to obtain required characteristics of concrete cracks. Different filters, such as - Linear filter, Gabor filter, statistical filter, Sobel's filter, median filter, have been applied to crack images to distinguish the crack information from the analogous background pattern by eliminating noise [8,9,10,11]. Crack identification even after the processing of images by using filters is difficult due to the presence of uneven reflection of light, noise and low contrast. Therefore, the introduction of binary image converted from processed image has been very popular and Otsu thresholding method for selecting the thresholding value for the purpose of binary image conversion is widely accepted [11-16].

Researchers have also successfully utilized Image analysis technique for crack detection and measurement of characteristics of the cracks in concrete for their experimental works $[17,18,19,20]$. Hamrat et al. [21] have 
utilized the image analysis method to identify crack propagation and measure the crack width in concrete of different strengths under flexure and compare them with conventional strain gauge, LVDT measurements. They found the image analysis method of great advantages and also near to failure.

The goal of this paper is to demonstrate how this new technology can be applied to reinforced concrete specimen testing in the laboratory by verifying crack widths retrieved from the image analysis method with microscopic crack widths measurements. For this purpose, eight reinforced concrete prisms were prepared. Axial load was applied to the reinforced concrete prism specimen gradually to form cracks under tension. Adopting the image analysis method, cracks formed during the test were detected and measured. Finally, all results obtained from the image analysis were verified against the results acquired using a hand held microscope.

\section{Experimental Program}

As a part of this experimental program, concrete prismatic samples were cast and all material properties were determined in advance. During the experiments, the formation of the cracks in concrete were captured by camera and cracks measurements were carried out by the image processing method using ImageJ software. Experimental program of this study is explained in the following sections.

\subsection{Material Properties}

Different properties of fine aggregate, coarse aggregate and binder, used in this experimental program, were determined according to the corresponding ASTM standards.

\subsubsection{Aggregates}

Sylhet sand and stone chips were used as fine and coarse aggregate, respectively. Different properties such as specific gravity, absorption, unit weight and fineness modulus (FM) are shown in Table 1 and Table 2.

Table 1. Properties of Fine and Coarse Aggregates

\begin{tabular}{|l|c|c|}
\hline \multirow{2}{*}{ Test Name } & \multicolumn{2}{|c|}{ Results } \\
\cline { 2 - 3 } & Fine Aggregate & Coarse Aggregate \\
\hline $\begin{array}{l}\text { Specific Gravity } \\
\text { (ASTM C127, C128) }\end{array}$ & 2.42 & 2.81 \\
\hline $\begin{array}{l}\text { Absorption } \\
\text { (ASTM C127, C128) }\end{array}$ & $3.25 \%$ & $1.4 \%$ \\
\hline $\begin{array}{l}\text { Unit Weight } \\
\text { (ASTM C29) }\end{array}$ & $1668 \mathrm{~kg} / \mathrm{m}^{3}$ & $1535 \mathrm{~kg} / \mathrm{m}^{3}$ \\
\hline
\end{tabular}

Table 2. Fineness modulus of Fine Aggregates (ASTM C 136)

\begin{tabular}{|c|c|c|c|c|c|c|}
\hline \multicolumn{7}{|c|}{ Fineness Modulus (FM) of Sand } \\
\hline \multirow{2}{*}{$\begin{array}{c}\text { Sieve } \\
\text { No. } \\
\text { (ASTM) }\end{array}$} & \multirow{2}{*}{$\begin{array}{c}\begin{array}{c}\text { Sieve } \\
\text { Opening }\end{array} \\
(\mathrm{mm})\end{array}$} & \multirow{2}{*}{$\begin{array}{c}\begin{array}{c}\text { Weight } \\
\text { Retained }\end{array} \\
(\mathrm{gm})\end{array}$} & \multicolumn{2}{|c|}{$\begin{array}{l}\text { Cumulative } \\
\text { Weight } \\
\text { Retained }\end{array}$} & \multirow[t]{2}{*}{$\begin{array}{c}\% \\
\text { Finer }\end{array}$} & \multirow[t]{2}{*}{$\begin{array}{l}\text { F.M. } \\
\text { Value }\end{array}$} \\
\hline & & & (gm) & $(\%)$ & & \\
\hline No. 4 & 4.75 & 9.0 & 9.0 & 1.8 & 98.2 & \multirow{7}{*}{2.78} \\
\hline No. 8 & 2.36 & 31.7 & 40.7 & 8.1 & 91.9 & \\
\hline No. 16 & 1.18 & 119.2 & 159.9 & 32.0 & 68.0 & \\
\hline No. 30 & 0.60 & 134.8 & 294.7 & 58.9 & 41.1 & \\
\hline No. 50 & 0.30 & 106.3 & 401.0 & 80.2 & 19.8 & \\
\hline No. 100 & 0.15 & 83.3 & 484.3 & 96.9 & 3.1 & \\
\hline & & & & 277.9 & & \\
\hline
\end{tabular}

\subsubsection{Binder}

Ordinary Portland Cement (OPC) was used as a binder material. Properties as Specific gravity, normal consistency, the initial setting time and final setting time of cement were determined according to corresponding ASTM standards and are summarized in Table 3.

Table 3. Properties of Binder

\begin{tabular}{|c|c|c|}
\hline Test Name & Results & Test Method \\
\hline Specific gravity & 3.10 & ASTM C188 \\
\hline Normal Consistency & $26.5 \%$ & ASTM C187 \\
\hline Initial Setting Time & 95 minutes & ASTM C191 \\
\hline Final Setting Time & 160 minutes & ASTM C191 \\
\hline
\end{tabular}

\subsubsection{Reinforcement Steel}

$16 \mathrm{~mm}$ and $20 \mathrm{~mm}$ diameter reinforcement steels were used in the preparation of prismatic reinforced concrete samples. The average yield strength and ultimate strength of $16 \mathrm{~mm}$ diameter bar were found to be $605 \mathrm{MPa}$ and 725 $\mathrm{MPa}$, respectively, whereas, the average yield strength and ultimate strength of $20 \mathrm{~mm}$ diameter bar were found to be $590 \mathrm{MPa}$ and $695 \mathrm{MPa}$.

\subsubsection{Sample Preparation}

Eight prismatic reinforced concrete samples were prepared in this study. The cross sections of all samples were $100 \mathrm{~mm}$ x $100 \mathrm{~mm}$ having length of $500 \mathrm{~mm}$, as shown in Figure 1 and Figure 2. One reinforcement bar was placed through the center of the samples. The reinforcement was $200 \mathrm{~mm}$ extended from both the top and bottom edges of the samples. All samples were divided into two groups consisted of 4 samples with one $16 \mathrm{~mm}$ diameter bar (S-16) and rest of the samples with one $20 \mathrm{~mm}$ diameter bar (S-20). All prismatic samples and three cylinders of $150 \mathrm{~mm}$ x $300 \mathrm{~mm}$ dimensions were cast from the same concrete mix to determine the properties of concrete at the time of the test.

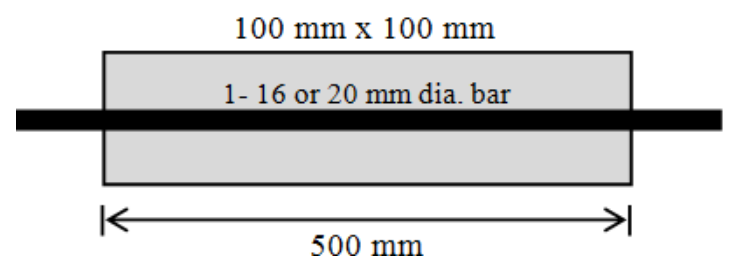

Figure 1. Schematic diagram of prismatic samples

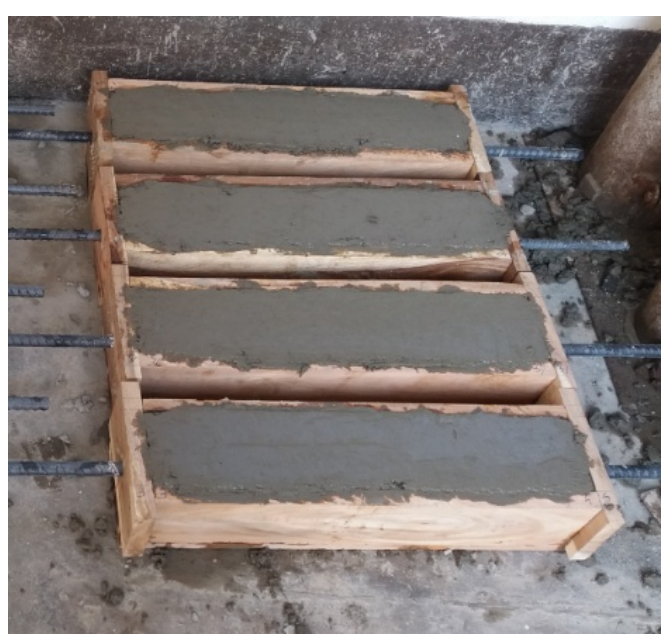

Figure 2. Preparation of Prismatic sample 
All the samples and companion cylinders were water cured for 28 days. The compressive strength test was performed according to ASTM C39 and the average compressive strength of concrete after 28 days was found to be $18 \mathrm{MPa}$.

\subsubsection{Test Setup}

All samples were tested under axial tension loading at 28 days of concrete age. For this purpose, samples with extended reinforcement were set to a Universal Testing machine as shown in Figure 3 for applying axial tension.

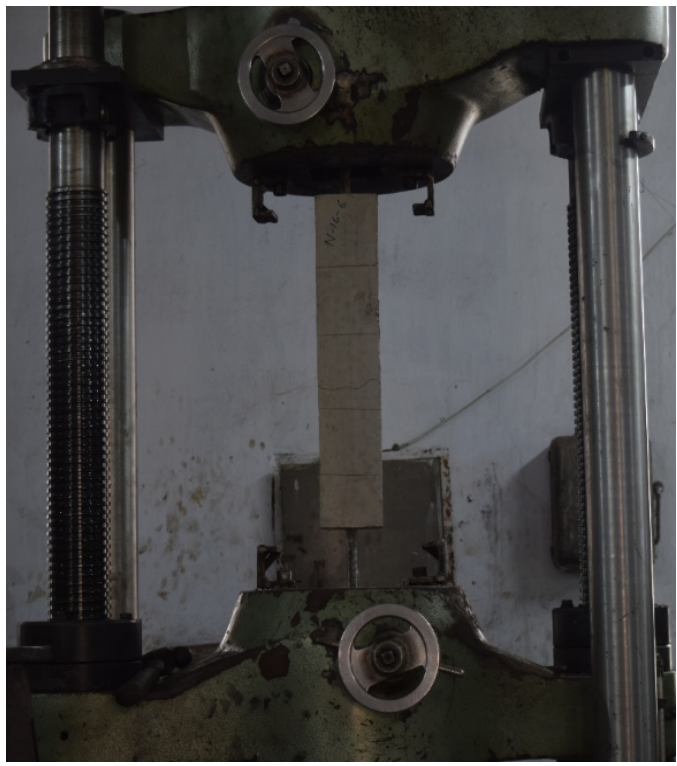

Figure 3. Test Setup for axial tension test of RC members

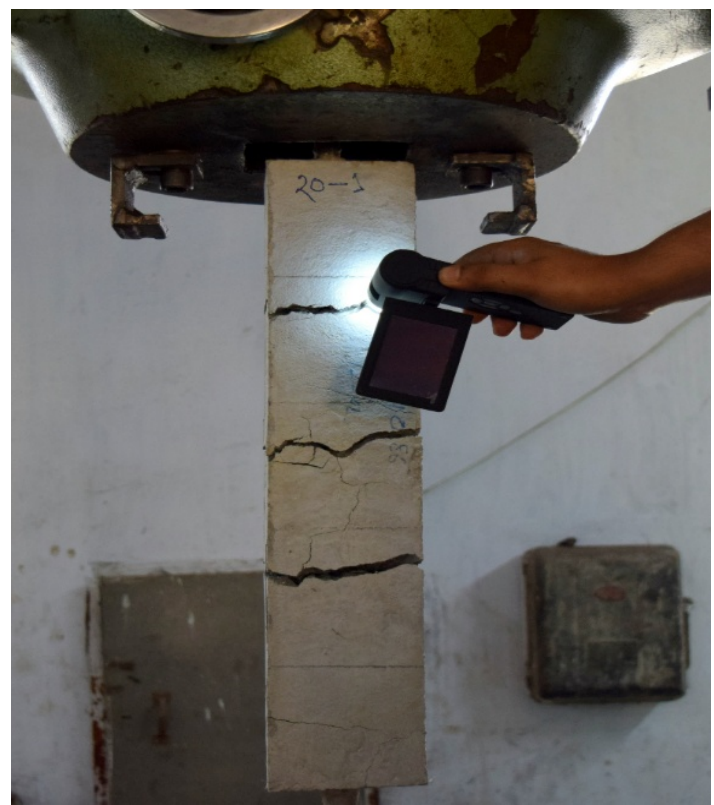

Figure 4. Crack measurement with microscope

Load was applied gradually during the tests and images were taken at a regular interval of $10 \mathrm{KN}$ load by a stationary camera for image analysis. A printable ruler was attached on the sample for reference scale. A hand handled Microscope was also used to measure the crack width and verify with the crack width obtained from image processing techniques as shown in Figure 4. To validate the results obtained from the image analysis method, crack widths were measured with a microscope at three different stages: at the onset of cracking, around 100 $\mathrm{kN}$ axial load and just before the ultimate load.

\section{Image Processing Technique}

In this paper, the image analysis procedure is adopted to capture the crack initiation and propagation process during the test of the prismatic samples under axial tension. During the test, concrete surface started to crack and image analysis technique offers a non-contact detection method of crack and consequently measure the characteristics of cracks developed.

In the image analysis method, a series of pictures of concrete surface are taken by a digital camera and all information related to crack initiation and propagation are acquired. However, light reflection and brightness may not uniform in all cases. In addition to that, concrete surfaces also suffer from an uneven finish, small pore and other noises. Therefore, it is required to process the acquired digital images of concrete surface to eliminate all these light variation and noises to precisely identify the cracks and measure their characteristics. Generally, image processing methods for identifying concrete cracks involves following steps - firstly raw colour image capture of the interested area of concrete surface, then transform the colour image to 8-bit gray-level image, subtract the background for uniform brightness, the application of filter for smoothness and finally thresholding to identify the cracks. Once the cracks are identified on the concrete surface, characteristics of the cracks measuring techniques are applied. The adopted image analysis method for crack detection and crack widths measurement was performed in open source ImageJ software and explained in the following sections:

\subsection{Acquiring Raw Colour Image of Concrete Surface}

Acquired images of the concrete surface of prismatic samples during the axially tension tests were processed and analyzed by ImageJ software to identify the crack and measure the crack widths due to the different level of loads. Images were captured by only one camera from one side of the sample. It was assumed that the concrete surface would crack symmetrically from all four sides since only reinforcement was placed in the center of the sample and was loaded concentrically under axial tension. After each test, all pictures were assigned to their corresponding load level and only the concrete surface part of the images were cropped using ImageJ.

\subsection{Transformation of Raw Colour Image to Gray Level}

Digital camera captures raw colour images with lots of information which are difficult to process. Therefore, colour images were converted to 8-bit gray level images for the convenience of further processing of those images. 


\subsection{Filter Application}

A smooth continuous background was subtracted from all the images to eliminate all the shading, uneven illumination and concrete surface noise. As a result of the background subtraction from the original gray-scale image, a mostly noise free image was able to obtain. Bandpass filter was also applied to all images to further enhance the edges of cracks of the concrete surface. The application of this filter connected the pixel gaps between crack lines and also regulated the crack shape.

\subsection{Binary image creation}

A pixel value which is lower than a predefined threshold value is assigned to 0 (Black) and all other pixels are to 1 (white). As a result, all gray-level images converted to binary images with only 0 or 1 . However, in binary image creation process, setting a threshold value is subjective and consequently could provide different result. Therefore, widely accepted Otsu method was adopted in this study for defining the threshold value. The binary image obtained using the threshold value determined by Otsu method contained cracks with welldefined edges.

\subsection{Crack width measurement}

After the identification of cracks in concrete surface, the crack widths were determined by "Ridge Detection" plug-in in ImageJ. All the steps involved in the cracks identification and crack width measurement are shown in Figure 5.

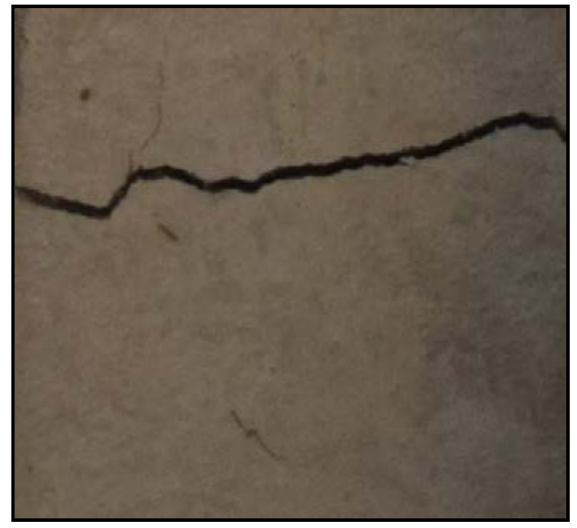

Figure 5(a). Raw colour image acquired during test



Figure 5(b). Transformation of colour image to gray level image

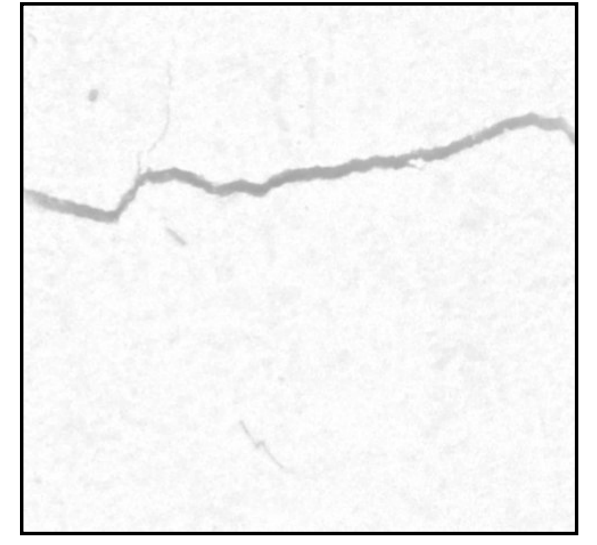

Figure 5(c). Background subtraction from gray level image

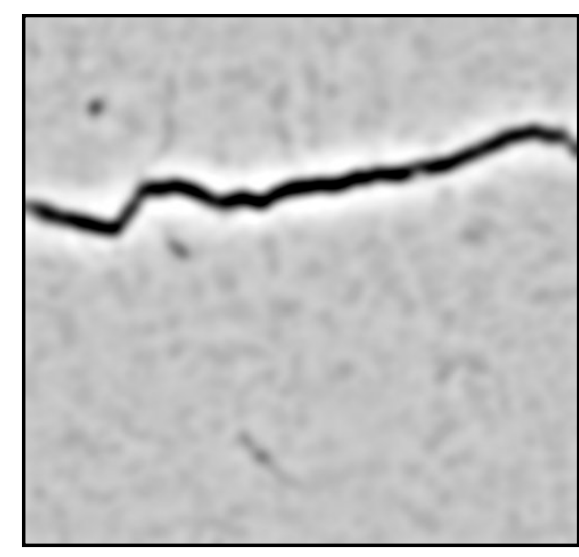

Figure 5(d). Bandpass filter application

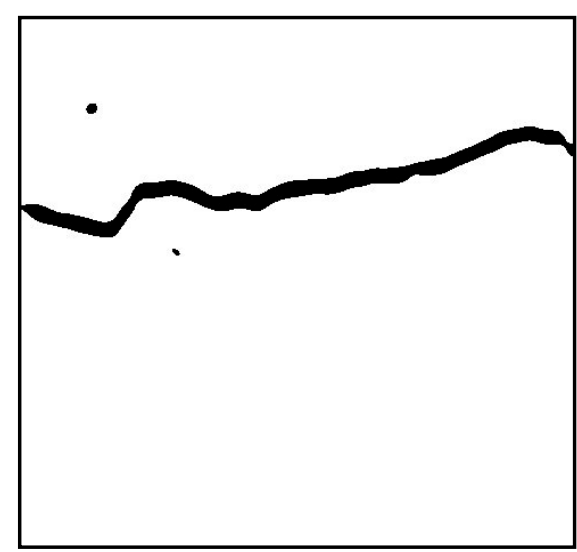

Figure 5(e). Otsu Thresholding

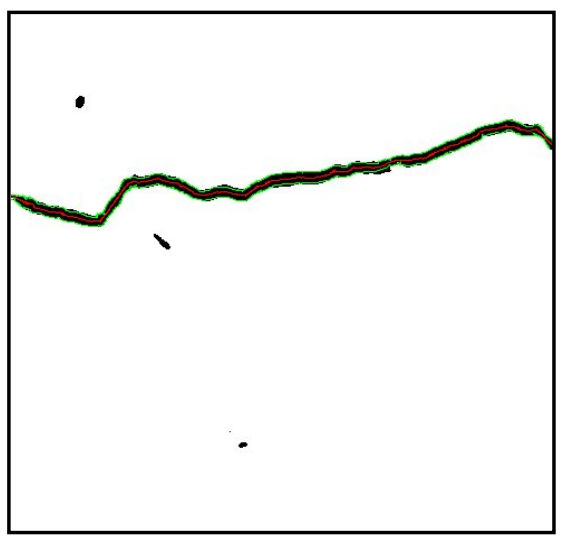

Figure 5(f). Application of Ridge detection for crack width measurements 
Cracks in concrete samples at three different levels of loads, at the onset of cracking, around $100 \mathrm{kN}$ axial load and just before the ultimate load, were also measured by hand held microscope, as shown in Figure 6.

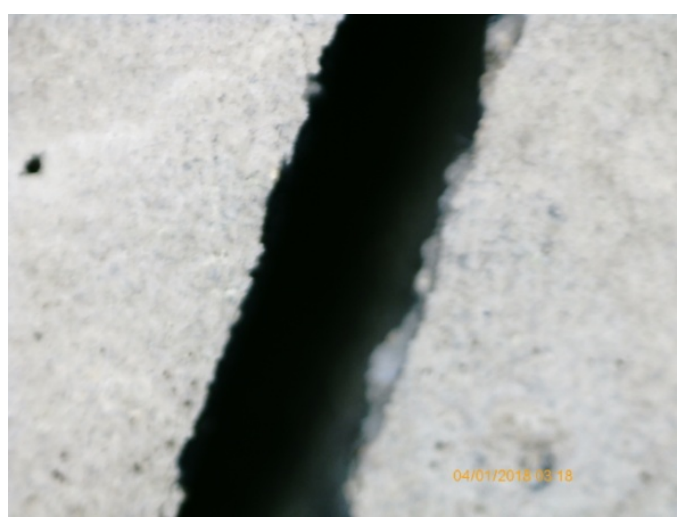

Figure 6. Image of crack width by microscope

\section{Test Result for Prismatic Beam}

In this paper, initiation of the cracks and their growth during axial tension tests were captured by images and characteristics of cracks were measured by the image analysis method. For all samples, the first cracks under tension were recorded at around $60 \mathrm{kN}$ axial load, irrespective of the diameters of the reinforcements. After the first cracking the widths of the cracks increased linearly with the increase of load until the load reached to the yield strength of the reinforcement, as shown in Figure 7. Crack widths measured by the image analysis method are also compared to crack widths measured by the microscope at three different levels of load, as shown in Figure 7. The comparison showed the effectiveness of the image analysis method in identifying and measuring cracks in concrete.



Figure 7(a). Crack width variation with load for sample S-16-1.

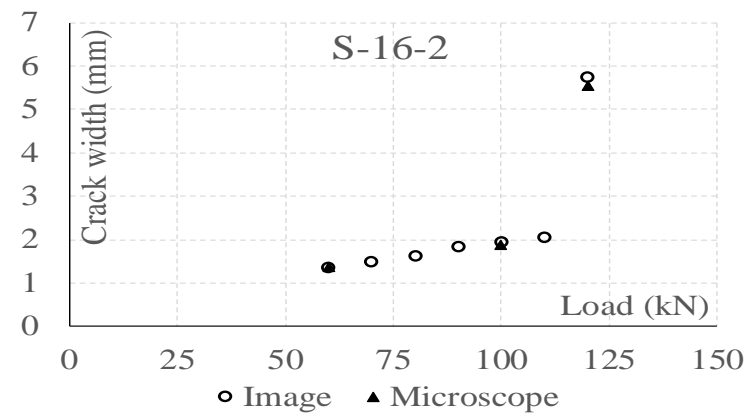

Figure 7(b). Crack width variation with load for sample S-16-2

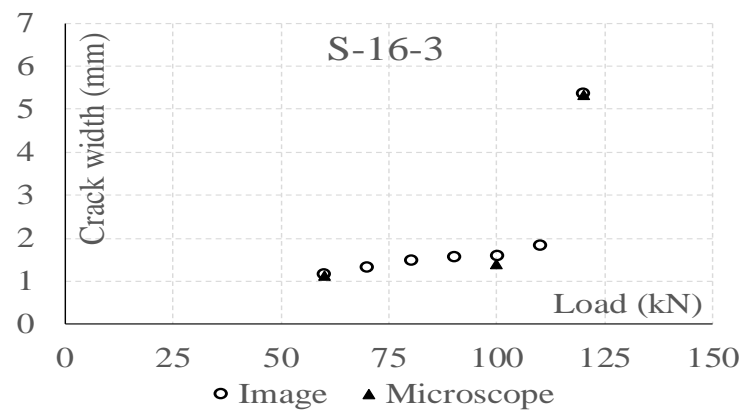

Figure 7(c). Crack width variation with load for sample S-16-3

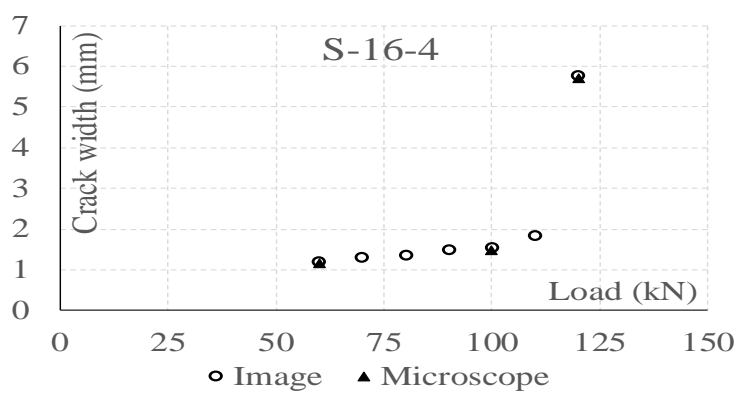

Figure 7(d). Crack width variation with load for sample S-16-4

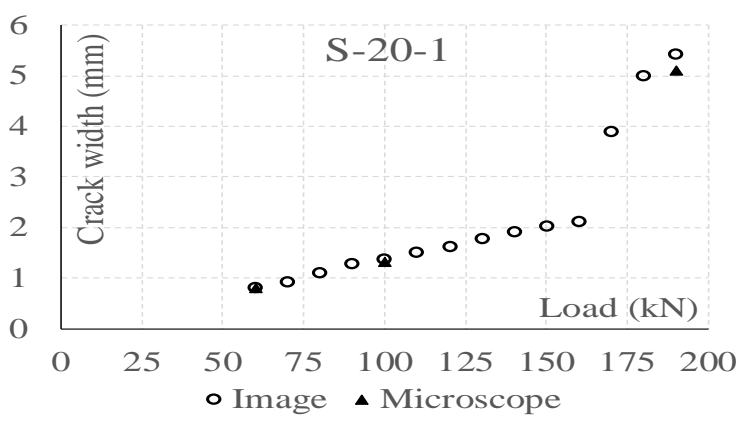

Figure 7(e). Crack width variation with load for sample S-20-1

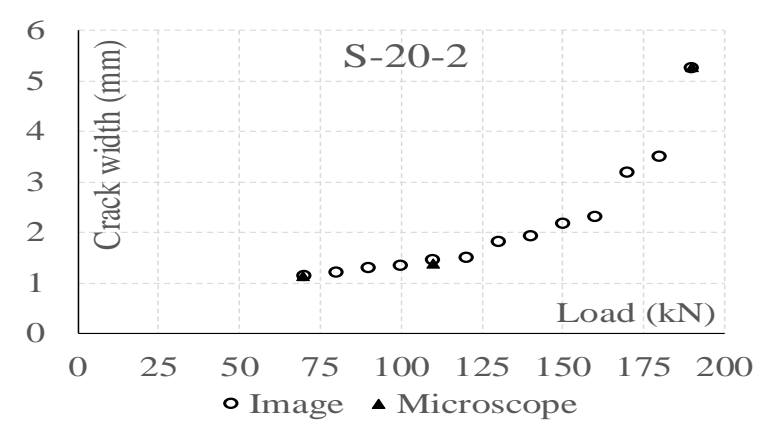

Figure 7(f). Crack width variation with load for sample S-20-2

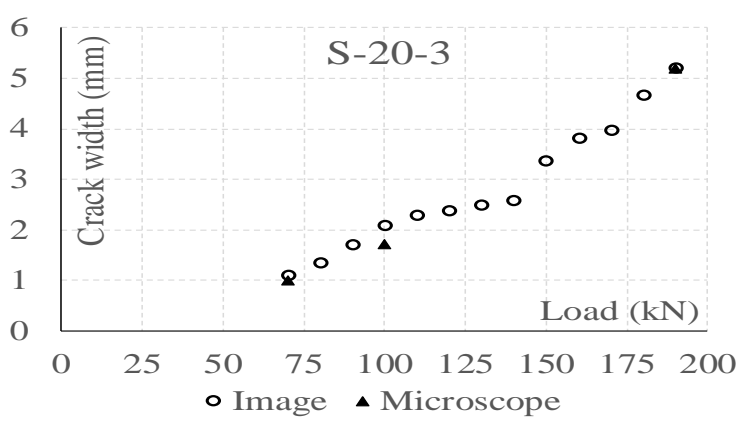

Figure 7(g). Crack width variation with load for sample S-20-3 


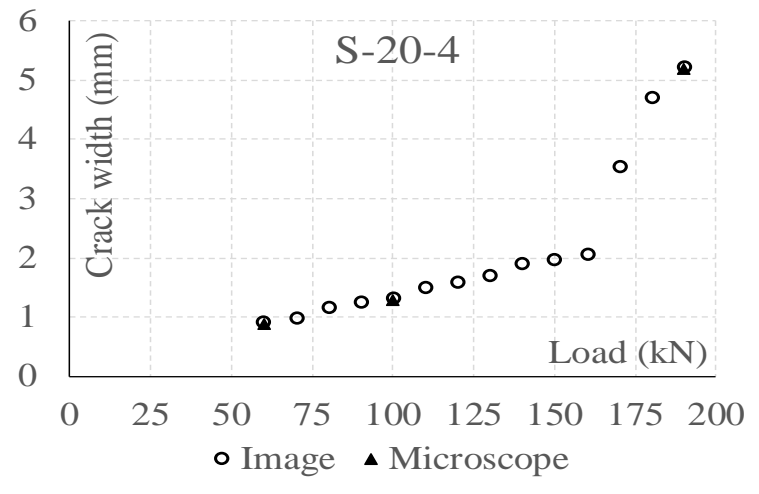

Figure 7(h). Crack width variation with load for sample S-20-4

\section{Conclusion}

This paper described a series of tests of eight prismatic reinforced concrete samples with only reinforcement placed through their center. All tests were carried out under concentric axial tension and the formation of cracking was observed. During the tests, initiation of cracks and cracks widths with different levels of loads were measured by the image analysis method using ImageJ software. The first crack in all samples occurred around $60 \mathrm{kN}$ of axial load. The image analysis method successfully captured and measured the crack widths in the concrete samples during the tests which were validated with the results obtained from microscope measurements of cracks.

\section{Acknowledgements}

The authors acknowledge the kind cooperation of all technicians of the laboratory of Department of Civil Engineering, Khulna university of Engineering \& Technology, Bangladesh, where all the experimental works of this study were carried out.

\section{References}

[1] Wu, X., Jiang, Y., Masaya, K., Taniguchi, T., \& Yamato, T. (2017). Study on the correlation of vibration properties and crack index in the health assessment of tunnel lining. Shock and Vibration, 2017.

[2] Adhikari, R. S., Moselhi, O., \& Bagchi, A. (2014). Image-based retrieval of concrete crack properties for bridge inspection. Automation in construction, 39, 180-194.

[3] Anil, E. B., Akinci, B., Garrett, J. H., \& Kurc, O. (2016) Information requirements for earthquake damage assessment of structural walls. Advanced Engineering Informatics, 30(1), 54-64.
[4] Torok, M. M., Golparvar-Fard, M., \& Kochersberger, K. B. (2013). Image-based automated 3D crack detection for post-disaster building assessment. Journal of Computing in Civil Engineering, 28(5), A4014004.

[5] Thatoi, D., Guru, P., Jena, P. K., Choudhury, S., \& Das, H. C. (2014). Comparison of CFBP, FFBP, and RBF networks in the field of crack detection. Modelling and Simulation in Engineering, 2014, 3.

[6] Koch, C., Georgieva, K., Kasireddy, V., Akinci, B., \& Fieguth, P. (2015). A review on computer vision based defect detection and condition assessment of concrete and asphalt civil infrastructure. Advanced Engineering Informatics, 29(2), 196-210.

[7] Wang, M. L., Lynch, J. P., \& Sohn, H. (Eds.). (2014). Sensor Technologies for Civil Infrastructures, Volume 1: Sensing Hardware and Data Collection Methods for Performance Assessment. Elsevier.

[8] Iyer, S., \& Sinha, S. K. (2005). A robust approach for automatic detection and segmentation of cracks in underground pipeline images. Image and Vision Computing, 23(10), 921-933.

[9] Salman, M., Mathavan, S., Kamal, K., \& Rahman, M. (2013, October). Pavement crack detection using the Gabor filter. In 16th international IEEE conference on intelligent transportation systems (ITSC 2013) (pp. 2039-2044). IEEE.

[10] Sinha, S. K., \& Fieguth, P. W. (2006). Automated detection of cracks in buried concrete pipe images. Automation in Construction, 15(1), 58-72.

[11] Talab, A. M. A., Huang, Z., Xi, F., \& HaiMing, L. (2016). Detection crack in image using Otsu method and multiple filtering in image processing techniques. Optik-International Journal for Light and Electron Optics, 127(3), 1030-1033.

[12] Rimkus, A., Podviezko, A., \& Gribniak, V. (2015). Processing digital images for crack localization in reinforced concrete members. Procedia Engineering, 122, 239-243.

[13] Alam, S. Y., Loukili, A., Grondin, F., \& Rozière, E. (2015). Use of the digital image correlation and acoustic emission technique to study the effect of structural size on cracking of reinforced concrete. Engineering Fracture Mechanics, 143, 17-31.

[14] Ebrahimkhanlou, A., Farhidzadeh, A., \& Salamone, S. (2016). Multifractal analysis of crack patterns in reinforced concrete shear walls. Structural Health Monitoring, 15(1), 81-92.

[15] Yu, T., Zhu, A., \& Chen, Y. (2016). Efficient crack detection method for tunnel lining surface cracks based on infrared images. Journal of Computing in Civil Engineering, 31(3), 04016067.

[16] Bose, K., \& Bandyopadhyay, S. K. (2016). Crack detection and classification in concrete structure. Journal for Research, 2(4), 29-38.

[17] Nguyen, H. N., Kam, T. Y., \& Cheng, P. Y. (2014). An automatic approach for accurate edge detection of concrete crack utilizing 2D geometric features of crack. Journal of Signal Processing Systems, 77(3), 221-240.

[18] Fujita, Y., \& Hamamoto, Y. (2011). A robust automatic crack detection method from noisy concrete surfaces. Machine Vision and Applications, 22(2), 245-254.

[19] Glud, J. A., Dulieu-Barton, J. M., Thomsen, O. T., \& Overgaard, L. C. T. (2016). Automated counting of off-axis tunnelling cracks using digital image processing. Composites Science and Technology, 125, 80-89.

[20] Ebrahimkhanlou, A., Farhidzadeh, A., \& Salamone, S. (2016). Multifractal analysis of crack patterns in reinforced concrete shear walls. Structural Health Monitoring, 15(1), 81-92.

[21] Hamrat, M., Boulekbache, B., Chemrouk, M., \& Amziane, S. (2016). Flexural cracking behavior of normal strength, high strength and high strength fiber concrete beams, using digital image correlation technique. Construction and Building Materials, 106, 678-692. 